\title{
Entertainment Attendants and Related Workers
}

National Cancer Institute

\section{Source}

National Cancer Institute. Entertainment Attendants and Related Workers. NCI

Thesaurus. Code C122449.

The ushers, lobby attendants, ticket takers, and projectionists employed in theaters, amusement and recreation attendants, costume attendants, locker room, coatroom, and dressing room attendants, and workers in the gaming and gambling industries. 